\title{
This Changes Sustainable HCI
}

\author{
Bran Knowles \\ Lancaster University \\ Lancaster, UK \\ b.h.knowles1@lancaster.ac.uk
}

\author{
Oliver Bates \\ Lancaster University \\ Lancaster, UK \\ o.bates@lancaster.ac.uk
}

\author{
Maria Håkansson \\ Chalmers University of \\ Technology \& RISE Research \\ Institutes of Sweden \\ Göteborg \& Borås, Sweden \\ maria.hakansson@ri.se
}

\begin{abstract}
More than a decade into Sustainable HCI (SHCI) research, the community is still struggling to converge on a shared understanding of sustainability and HCI's role in addressing it. We think this is largely a positive sign, reflective of maturity; yet, lacking a clear set of aims and metrics for sustainability continues to be the community's impediment to progressing, hence we seek to articulate a vision around which the community can productively coalesce. Drawing from recent SHCI publications, we identify commonalities that might form the basis of a shared understanding, and we show that this understanding closely aligns with the authoritative conception of a path to a sustainable future proffered by Naomi Klein in her book This Changes Everything. We elaborate a set of contributions that SHCI is already making that can be unified under Klein's narrative, and compare these categories of work to those found in past surveys of the field as evidence of substantive progress in SHCI.
\end{abstract}

\section{Author Keywords}

Climate change, sustainability, sustainable HCI, reflective $\mathrm{HCI}$

\section{ACM Classification Keywords}

H.5.m. Information Interfaces and Presentation (e.g. HCI): Miscellaneous

\section{INTRODUCTION}

In the past decade, Sustainable HCI (SHCI) has been working to develop a robust understanding of sustainability as a solid premise from which to envisage meaningful, high impact HCI interventions. Early conceptions of SHCI's role as delivering incremental reductions in energy consumption (from IT and by individuals) have come under criticism in recent years as being insufficient for the scale of the problem [48, 59], shifting responsibility onto those with the least power to affect real change $[35,48]$, and reinforcing a problematic modernist/neoliberal worldview $[7,25,96]$. In response, many

Permission to make digital or hard copies of all or part of this work for personal or classroom use is granted without fee provided that copies are not made or distributed for profit or commercial advantage and that copies bear this notice and the full citation on the first page. Copyrights for components of this work owned by others than ACM must be honored. Abstracting with credit is permitted. To copy otherwise, or republish, to post on servers or to redistribute to lists, requires prior specific permission and/or a fee. Request permissions from Permissions@ acm.org.

CHI 2018, April 21-26, 2018, Montreal, QC, Canada

(C) 2018 Association for Computing Machinery.

ACM ISBN 978-1-4503-5620-6/18/04\$15.00

https://doi.org/10.1145/3173574.3174045 (e.g. $[48,71,82])$ have argued for the adoption of more radical conceptions of sustainable futures than had tacitly underpinned seminal SHCI works (i.e. such as $[6,60]$ ), but as yet there is no unified vision of SHCI's role in addressing sustainability.

The closest the community has come to a consensus view of SHCI's role was the publication resulting from the 2014 SIGCHI HCI \& Sustainbility Community workshop [92]. This workshop and publication represented an important turning point in SHCI's history, when the community articulated the challenges we face in doing SHCI work, and laid out a clear set of standards for SHCI going forward. One of these standards was for "SHCI research [to] articulate clear study- or design-specific sustainability goals and metrics on a project-by-project basis" [94]. This was, at the time, a tactful way of resolving the fact that "most of the 23 participants rejected the idea that we could devise a single interpretation of sustainability to orient and evaluate all future SHCI research," and mollifying the heated disagreement among participants as to whether sustainability is a "process" or an "endpoint" [94]

Three years later, we believe that this compromise is no longer serving the community. Embracing myriad competing researcher- or paper-specific definitions of sustainability has the potentially disunifying effect of making it seem as if there is more dividing us than there really is. We argue that cohesion is better sought, therefore, through establishing an intellectually sound understanding of sustainability that is capable of inspiring the whole SHCI community. We don't deny sustainability is a contested term [16, 18, 62]; nor do we believe that nuance isn't important (e.g. what specific values should the individual or community adhere to?). Our point, however, is that focusing on the differences between these definitions, while an important part of the learning process for us as a community up to this point, prevents us from recognizing the commonalities that we could make progress toward together now, urgently.

In this paper, therefore, we aim to dispel the myth that there is such variation in conceptions of a way forward for SHCI that we cannot clearly see two dominant (if competing) views emerging from the community. The first of these two views is that small scale reductions in energy consumption and minor corrections to the ways people accomplish their goals will suffice (in the aggregate) for maintaining society as we know it in perpetuity. The other is that in order to sustain the quality of life for humans on this planet into the very far future, 
significant changes are needed to our current way of life. In our opinion, only one of these views holds water-the former having been most convincingly debunked by Mankoff [59], collectively rejected at workshops including [81] and [92], and critiqued in numerous publications including [7, 47, 48, $71,82,86]$.

We argue that the SHCI community ought to unite around the latter notion in order to achieve greater and more lasting impact. To more fully elaborate this view, we draw from Naomi Klein, author of This Changes Everything: Capitalism vs the Climate [46], as an authoritative voice on sustainability. We propose not only that we may import from her a clear and internally consistent vision of sustainability upon which to hang a vision of SHCI going forward, but further, as seen in the numerous works seeking to catalyze significant change (cited and explored at length in the section entitled Reconciling SHCI with Klein, below), that SHCI has already arrived at an understanding that aligns with Klein's. We articulate implications for SHCI going forward which reflect the evolution of thinking within SHCI and would substantively contribute toward affecting the change argued for by Klein. We hope that by doing so, the community may move beyond continual re-definition of sustainability and SHCI, and instead move swiftly and with greater conviction toward realizing high impact contributions.

\section{THIS CHANGES EVERYTHING}

In what follows we present at some length our understanding of the argument laid out in Naomi Klein's book, This Changes Everything: Capitalism vs The Climate [46]. Taking this space is necessary for exploring in subsequent sections how there is already support for this argument as demonstrated by prior works in SHCI, and for drawing out elements of an agenda already proposed in such works that aligns with Klein's argument.

\section{The thesis}

Klein's work finds its impetus in the present global crisis of climate change - the average warming of the planet through the release of increased amounts of greenhouse gasses into the planet's atmosphere, causing a range of detrimental effects including extreme weather events, sea level rise, crop failure, draughts, coral bleaching, and mass extinction. Citing the most respected climate scientists and scholars-and echoing (among these) James Hansen's statement that staying within our carbon budget is essential "[i]f humanity wishes to preserve a planet similar to that on which civilization developed and to which life on Earth is adapted" [33] -Klein shows that continuing on our current trajectory will lead us toward 4-6 degree Celsius warming above pre-Industrial levels, i.e. toward a world that is uninhabitable and a future that is unrecognizable. "All we have to do to arrive at that place," she says, "is nothing" $[100]^{1}$.

\footnotetext{
${ }^{1}$ We will be quoting liberally from both Klein's book [46] and the condensed summary she presented at a The Guardian event in December 2014 [100]. We structure our summary of Klein's thesis closely following the latter.
}

The question at the heart of her investigation is why, having lost all "plausible deniability" of the link between greenhouse gasses and global warming in 1988, have we failed to respond in ways that would prevent this dire future. She argues that this failure is largely due to "historical bad timing" [100], in that the awareness of this impending crisis arrived at the very moment of neoliberal triumphalism. This ideology asserts that there is no viable alternative to the free market, and that unfettered capitalism is the quickest and most assured route to profits that will benefit all; and unfortunately for us, Klein argues, "That mindset clashes directly with the most obvious things that we need to do to rise to this challenge" [100].

Anathema to this logic, firstly, is the notion of large-scale investment in the public sphere required for step change in emissions and preparation against the extreme weather events we have already ensured through our inaction. Furthermore, while there is money to be found for this investment (e.g. through taxing emissions), the neoliberal worldview abhors the notion of any investment in 'the collective' that curtails the profits of corporations. The privatization of utilities and other services, another hallmark of this form of capitalism, also makes responding to this crisis as a collective that much more challenging. But in recent years, the greatest impediment to building a society that will save us from climate induced catastrophe is "the procrastination penalty": the fact that having stalled for so long, we must now reduce our emissions by $8-10 \%$ per year. There are at this late stage "no non-radical options left on the table" [100]; we are "facing cuts so drastic that they challenge the core expansionist logic at the heart of our economic system" [46, p. 87], and the solutions, therefore, "become ideologically heretical in our times" [100]:

What the climate needs to avoid collapse is a contraction of humanity's use of resources; what our economic model demands to avoid collapse is unfettered expansion. Only one of these sets of rules can be changed, and it's not the laws of nature [46, p.21].

And we are stuck here, on a trajectory of annihilation, "because the actions that would give us the best chance of averting catastrophe-and would benefit the vast majority-are extremely threatening to an elite minority that has a stranglehold over our economy, our political process, and most of our major media outlets" [46, p. 18]. Klein summarizes: "In short, we have not responded to this challenge because we are locked in - politically, physically, and culturally. Only when we identify these chains do we have a chance of breaking free" [46, p. 63].

So what does it mean to 'break free'? It means that if the 'free' market is fundamentally incompatible with rapid emissions reductions [46, p. 21], then we must plan a radically different, 'justice-based' economy ${ }^{2}$. "Encouraging the frenetic and indiscriminate consumption of essentially disposable products can no longer be the system's goal" [46, p. 85];

\footnotetext{
${ }^{2}$ That there will be a transition in the future is not contested by Klein; but she argues there is no guarantee, and indeed no reason to believe from precedent, that the transition we make in response to climate change will be a just one [100].
} 
and the policies underpinning this new economy would include "sweeping bans on polluting activities, deep subsidies for green alternatives, pricey penalties for violations, new taxes, new public works programs, [and] reversals of privatizations" [46, p. 40] - all of which are contrary to the dominant neoliberal worldview.

Subverting long-held (but not necessarily consensus) conceptions of sustainability as being comprised of three overlapping pillars - environmental, social and economic-Klein argues that because climate change forces us to square off between our own survival and the survival of our economic system, this crisis is the best reason we have ever had "to advance a plan to heal the planet that also heals our broken economies and our shattered communities" [46, p. 155]:

It's not like we're talking about an economic system that is working beautifully except for the small matter of rising sea levels. We're talking about allowing sea levels to rise in the name of protecting an economic system that is failing the vast majority with or without climate change. This is a system that has already sacrificed a great many people's job security, their homes, their right to a good public education, to decent healthcare; and now that same system is making it clear that it is willing to sacrifice the stability of the planet's life support system. So it's high time we go after the underlying logic behind all of these crises [100].

\section{The plan}

A significant portion of Klein's book is devoted to debunking the notion that there is a way of reconciling climate change with contemporary capitalism, i.e. that the market will produce, out of opportunity and necessity, businesses that thrive by doing the 'green' thing. This is "a hypothesis that has been tested and retested in the real world" [46, p. 252], repeatedly failing due to the outsized profit incentives which inevitably trump the environmental cause. What this shows is not that those attempting to innovate in this space are illintentioned, but rather that changes to industry "won't happen on a voluntary basis or on the honor system. It will have to be legislated-using the kinds of tough regulations, higher taxes, and steeper royalty rates these sectors have resisted all along" [46, p. 254]. It will also require that the fossil fuel industry is forced to write off $80 \%$ of their reserves and the profits they would make from them, in order to keep us in the 'safe' zone:

All of this is why any attempt to rise to the climate challenge will be fruitless unless it is understood as part of a much broader battle of worldview, a process of rebuilding and reinventing the very idea of the collective, the communal, the commons, the civil, and the civic after so many decades of attack and neglect [46, p. 460].

This means that everyone must take part in the project of building a society based on a different worldview in a way that is "deeply woven into the project of life" [46, p. 459]. Historical precedent proves that "major shifts in the economic balance of power... are invariably the result of extraordinary levels of social mobilization" [46, p. 459]. We need, therefore, to reinvigorate democracy $[46, \mathrm{p} .10]$, to ignite a mass movement of regular people declaring a crisis [46, p. 6], and most of all, for people to see in climate change both the threat and the opportunity; to experience "rage at injustice and hope at another kind of future" [100]. Our only hope in preventing humanity-threatening climate change, therefore, is a mass social movement that fights for the rights of the majority, that demands fairness and equality and justice. This movement will only be successful if it recognizes and attends to the socio-economic predicament that underlies unabated climate change, namely that of systemic inequality. This requires challenging the neoliberal logic that has rationalized this inequality, championing the unquestionable morality of a more equitable society, and instigating a massive shift in economic power and redistribution of wealth to rectify this abhorrent imbalance. Only then will we have the strength to reject the profit-driven extractivism ${ }^{3}$ that has led to environmental denudation and climate destroying pollution; and in addressing the root cause of this climate crisis we may finally fulfil the long-awaited ambition of so many social movements throughout history to create a world truly worth sustaining.

\section{IMPLICATIONS FOR SHCI}

In this section we present a set of high level takeaways from Klein's work, followed by set of emergent categories of work within SHCI that would appear to align with Klein's thesis.

\section{Takeaways}

Orient around climate change, rather than 'sustainability'

SHCI has not as yet focused on climate change, preferring instead to consider sustainability more 'broadly' as a multifaceted and multiscalar set of issues [94]. Klein's work shows why it is both legitimate and politically expedient to begin from climate change, i.e. because when understood in this way, climate change "neither trumps nor distracts from our most pressing political and economic causes: it supercharges each one of them with existential urgency" [46, p. 153]. Climate change is "the big tent we have all been waiting for" [100], and it can and should be that big tent under which SHCI coalesces with shared purpose. Without excluding the many concerns represented within SHCI's portfolio (e.g. pollution, draught, food shortage, waste, economy, social justice, etc), climate change provides much needed narrative clarity to unify the community when engaging in a broad set of otherwise seemingly disconnected activities.

\section{Develop a new model for the digital economy}

The need for $8-10 \%$ reduction in emissions per year does not mean, necessarily, that each industry will reduce at an equal pace. But this target does put into rather harsh perspective the scale of the reductions SHCI has been aiming to enable to date (cf. [59]). As Klein showed with her analysis of the predicament we face with the wider economy, this pace of reductions is incompatible with the treadmill of technological innovation that spurs continuous consumption and disposal [88], and is therefore incompatible with the continued profitability of the sector as we know it [91]. The only viable

${ }^{3}$ Defined as the mentality at the heart of materialism which has been carried over into modern capitalism [46, p. 25], which manifests as extraction of resources from the earth without regard to the limits of the regenerative biocapacity of earth systems (see also [46, p. 169]). 
alternative would be developing "technologies relying less on instrumental purposes of efficiency connected with corporate profit... (motivated by research paradigms grounded in the belief of infinite economic growth) and relying more on volitional and value-laden aspects underlying people's use of technologies" [73]. This would also mean developing new ways of measuring the success of the industry, which considers human and ecological consequences above growth, and works to foster above all justice and wellbeing [27].

The question we must grapple with-as we are when considering Klein's proposed the changes to the wider economyis how to make that transition ${ }^{4}$. What role is/are SHCI as a community and SHCI researchers individually, going to play in ushering in the change that is required? Answering this question, we believe, should be the central and defining task of SHCI. This suggests an altogether different role for SHCI researchers, requiring that we engage with the wider $\mathrm{HCI}$ and ICT communities, helping to shape computing outputs beyond those we in SHCI are directly involved in developing.

\section{Fighting injustice and inequality on all fronts}

Klein points out that local resistance to the fossil fuel industry often fails due the economic desperation of people in those communities [46, p. 94], who cannot afford to pass on the deal they are being offered ${ }^{5}$. "With many of the biggest pools of untapped carbon on lands controlled by some of the poorest people on the planet," Klein writes, "and with emissions rising most rapidly in what were, until recently, some of the poorest parts of the world, there is simply no credible way forward that does not involve redressing the real roots of poverty" [46, p. 418]. It is imperative that while reducing its own emissions, the digital economy is designed to close the gap between the rich and the poor and to create (rather than eliminate) good paying jobs around the world [40, 89, 93] with systems that enable casual labor and short-term contracts perhaps not being this solution (cf. [66]). It also means that while we explore ways for the West to reduce its emissions, we invest heavily in "develop[ing] differently" in the developing world [46, p. 414] — broadening our focus to the developing world as a site for implementing some of our more ambitious projects, which are in the West practically conceived as 'design fictions'. This suggests a natural alliance to be cultivated with the HCI for Development (HCI4D) community, which has thus far been relatively distinct from SHCI.

\section{Helping to build and support a mass movement}

One of Klein's central ideas is that "the only way you can win against forces with a huge amount to lose is to build a movement of people, many more people, with a huge amount

\footnotetext{
${ }^{4}$ As daunting as it may seem to design to a new economic model, Ekbia \& Nardi [27] remind us that it has been done before: "the capitalist system has re-invented itself a number of times in the last century or so, changing drastically along the way... [and] parallel changes in computing have occurred."

${ }^{5}$ Partly for this reason, and because they have the strongest legal grounds for protesting continued resource exploitation, "historical claims being made by Indigenous peoples around the world as well as by developing countries for an honoring of historical debts indeed have the potential to act as counterweights to increasingly undemocratic and intransigent governments" [46, p. 366].
}

to gain" [100]. To generate critical mass, this would mean harnessing the potential of ICT as a communication medium to be deployed both at scale and by local groups organizing on the ground; as well as helping heighten the visibility and effectiveness of activism that is already occurring (cf. [1, 9, $15,28,30,31,48,77,87,108]$, arguing for developing systems to support activism). But it also means giving people the tools for responding to the crisis in meaningful ways, in contrast to taking actions such as emailing a congressperson, posting commentary on social media, or signing an e-petition [46, p. 296] - that is, developing a vision of technology's role in fostering invigorated, engaged and effective democracies (cf. [24, 55, 61]). But simultaneously, this means being part of the messaging about what people have to gain from this transition, e.g. offering an enticing vision of the alternative digital economy (above) and of next generation democracy, as we have been doing with design fictions.

\section{Fostering values-based debate}

Klein argues that central to the success of the movement is opening up "a space for a full-throated debate about valuesabout what we owe to one another based on our shared humanity, and what it is that we collectively value more than economic growth and corporate profits" [46, p. 461]. Prior SHCI work (the authors' own, included) have proposed a role for SHCI in designing interfaces that subtly encourage a set of self-transcendent values over self-enhancement values [47, 51], but this does not go far enough. Creating that dialogue starts with examining and challenging the values that underpin our own industry (cf. [91]), and (again this comes back to the need for a new digital economy) offering an alternative that is compatible with substantive change toward addressing climate change. Meanwhile, HCI may radically re-conceive the interactive models underpinning ICTs and social media, moving beyond 'forums' and 'posts', to develop the kinds of platforms to support real debate (cf. [68]).

\section{Bracing for impact}

Even if we were to arrest further climate change in an instant, there are consequences of the warming to date that we cannot avoid, including the kinds of extreme weather events we have been witnessing in recent times. As Klein points out, these consequences are not equally (or justly) distributed - the poor invariably suffer most. SHCI can help mitigate the worst of these effects by developing technologies that "support a high quality of life" [103] in the worst case scenario. Further, in addition to the investment required to make key physical infrastructure resilient to these impacts, it is important to ensure that the technological systems upon which society has come to rely are also resilient to extreme weather, as well as being able to operate in conditions where resources for powering them are less reliable or abundant.

\section{Reconciling SHCl with Klein}

There is no concealing the fact that we think Klein offers a superior analysis of the "issues indexed by the term sustainability" (to borrow a phrase from [94]) and how to affect necessary changes. But our opinion is beside the point. What we hope to show is that, for a community that has agonized over 
how we resolve (or at least make progress despite) the apparent differences in perspectives on sustainability and SHCI's role in addressing it, SHCI has produced a significant body of work that aligns with Klein, and therefore these publications can be reconciled with each other by adopting Klein's thesis as common ground.

We have already identified some of the similarities between the implications drawn from Klein's work and recent SHCI work, above-and savvy readers may have intuited further connections. Below, we clearly articulate the similarities as we see them, identifying several emergent (not necessarily discrete) categories of SHCI work that seem synergistic with the narrative outlined earlier. We note that this is not a comprehensive list of all activity within the field; instead it is a significant segment of this overall activity that can be unified to produce a coherent research agenda for the community.

\section{Systems thinking}

There is a clear theme within recent SHCI work that sustainability and unsustainability are conditions of a "system as a whole" [26]. Within this view, sustainability interventions must be conceived of and evaluated between different scales, over longer timeframes, and across a greater diversity of stakeholders [26, 94, 101, 102]. Researchers have argued that the 'sustainability' of individual ICTs must be considered within the 'ecology of devices' within which they are connected [2,3], and within the wider context of practices which constrain an individual's potential interactions [7, 19, $65,97]$. SHCI work has further contended that the route to affecting more sustainable practices is through affecting the even wider 'political ecology', comprised of institutions, infrastructures and cultural norms [43, 25, 52, 57, 63, 69, 73, 84]. This category of SHCI contribution is characterized by ethnographic investigations of situated practice, and by critique/agenda setting papers that argue for the need to develop solutions that affect systems-level change.

\section{Computing within ecological limits}

A growing body of work within SHCI takes the stance that although there may be a variety of aims associated with sustainability (e.g. well-being), there are also concrete aims determined by ecological systems. Key among these, the planet has a finite amount of natural resources that can be extracted, and can absorb a finite amount of waste (e.g. greenhouse gas emissions). These limits are knowable within a certain margin of error. Echoing Klein's assertion that climate rules cannot be bent [46, p. 21], SHCI researchers have begun to insist that the fact that ecological limits are "non-negotiable" [71] means that SHCI ought to adopt these limits as the basis for more ambitious (and more valid) research aims [48, 71, 26]. Works of this type tend to delineate a set of contributions SHCI can make and means of evaluating SHCI's success in attending to these limits.

\section{Future proofing}

Another concern regards the consequences of exceeding ecological limits. By all indications, civilization is on track to surpass the climate 'limit'; we will soon reach the limit of the availability of natural minerals needed to support computing technology $[10,72,88]$; and we will soon not have enough food and water to sustain the growing human population. Most likely, the impacts of exceeding these limits will be unequally distributed, with the poor facing the worst of the consequences. A body of work (originating in the Collapse Informatics discourse, a.k.a. Adapative Informatics [41, $72,105])$ focuses on developing technologies that mitigate the impact of "collapse", so that society can adapt to a future of scarcity in a comparatively just way [72]. SHCI proposes to do this by using ecological limits to bridge computing with other concerned communities [10,17], encouraging new models for sustainable self-sufficient computing [37], and to design software that is less reliant on industrial infrastructure that is able to function in times of intermittent resource access or collapse [72, 78]. Ultimately, this work proposes that SHCI should be more thoughtful about when to design (cf. [5]) and be more strategic in how we consider ecological limits in the technologies we propose in our future visions.

\section{Confronting the economy}

Some work in the above category maintains that predicted reduction economic growth is a likely catalyst for economic and then societal collapse. This is not wrong per se, but it assumes the economy as a natural fact (cf. [25]), precluding the ability for us to re-negotiate its nature. A number of SHCI works have pointed out the extent to which ICTs have shaped the economy [27, 38, 56, 70] — for good or for bad — and have argued that HCI can harness this potential to affect a justice based economy [27, 34, 66, 64, 91]. Many of these works propose new design sensibilities: for example, considering whether technology disproportionately benefits a particular class of people [27], or democratizing technological production [99]. Others propose designing to support positive and just economic transactions [13, 34, 54, 106], or supporting various agents on the ground who "seek to transform existing social arrangements, such as the norms of increasing economic growth and maximizing shareholder returns without regard to ecological or social consequences" [91] (cf. [12]). Such work aligns with the notion that unfettered free market capitalism and the ideology of neoliberalism themselves must be challenged, e.g. through actively interrogating how these manifest in the digital economy.

\section{Supporting local communities and infrastructures}

De-centralization of (e.g. energy) infrastructure is one means for communities to exert control over their locales and foster resilience, while also generating profits that stay within the community [46]. Aligning with this tactic, a new area of SHCI research has been proposed that explores the role for ICTs in designing alternative, decentralized infrastructures [104]. Other related work explores how local resilience manifests on the ground as providing insight into such design work [76], how technology may help individuals transition to time-variable locally generated energy supplies [95], and how to foster thriving local agriculture [29, 36, 85]. Collectively, these works seek to affect change through fostering independence and lasting resilience of local communities [73, 91].

\section{Advocating social justice}

While generally separated from mainstream SHCI under the heading of 'social sustainability' [8] — and rarely seen as key 
to arresting climate change (excepting [45]) - -there is a significant body of work at the nexus of SHCI and HCI4D that focuses on issues of social justice pertaining to ICTs. Of particular note, though not an SHCI publication, Dombrowski et al. [23] elaborate design strategies that embody a "social justice orientation" to addressing wicked problems such as sustainability (see also [11, 44, 72, 109]). Some other work in this category critiques the ways in which HCI research may inadvertently perpetuate bias and inequality, and advocates instead for postcolonial approaches [39, 67]. Other work focuses on how ICTs may intervene to address local manifestations of inequality, e.g. food insecurity [22], health disparities [74], and economic (im)mobility [42]; while others focus on ways for ICTs to foster discourse around past injustices [109]. Also relevant to this category is HCI work on gender equality and empowerment (e.g. [90]). These works represent a commitment to, at a minimum, ensuring that technologies do not exacerbate inequality and injustice; and where possible they manifestly reduce them.

\section{Inspiring with future visions}

There is a growing body of work in SHCI that aims to provide the kind of inspiring vision of a sustainable future needed to motivate a mass movement. Design fiction has been used as a technique for exploring the role of ICTs in alternative, sustainable futures [79, 83, 107], and for enabling designers to engage proactively with depressing futures [98]. There is real potential, however, for SCHI to not only sketch a future that the public can aspire to, but also by freeing ICTs from the norms currently operating on HCI, SHCI may affect change toward fundamentally different, sustainable futures (cf. [58]).

\section{Reimagining (digital) civics}

If what is needed to arrest climate change is a mass movement of people who are actively engaged in democracy, it is encouraging that recent HCI work (again, not necessarily badged as SHCI) explores the role of technology in revitalizing civic participation. These works explore challenges including how to motivate engagement in civic issues such as climate change [48, 68, 80, 84], how to enable citizens to engage in impactful civic participation (beyond 'clicktivism') $[15,28]$, how to replicate successful social movements [14], and how ICTs may enable coordination between civic actors [1]. Other related work has proposed that SHCI researchers themselves embrace their role as activist/citizen [9, 48, 102], though further discussion is sorely needed around whether and how some (or all) of us doing SHCI may transition to this dual role.

\section{Embracing and accounting for the political}

Finally, related to the above, critiques have surfaced regarding the notion that technology (or we as researchers) can or should be apolitical [20, 25]. Given this, there is both freedom to embrace and obligation to fully account for the political aspects of SHCI research and proposed technological interventions [27, 48, 84, 86]. In particular, recent works have argued strongly for engaging with climate change as an inherently moral issue, i.e. recognizing that it originates from a system that rewards and entrenches inequality and injustice [45, 50, 67]. While not prescriptive of a way forward, these works effectively absolve the community from having to justify SHCI activities in terms of how they otherwise contribute towards modernist goals such as efficiency or economic growth (see [7]), and enable us to pursue agendas that are uninhibited by or even in conflict with such goals.

\section{DISCUSSION \\ What does progress look like?}

In conducting our analysis of the threads connecting various SHCI publications, what we have certainly not done is a systematic literature review. We have selected for discussion only those papers that we see as capable of sharing a common narrative about sustainability (and we may have missed some). That being the case, it is still worth comparing the kinds of categories we found in recent work with those identified in prior systematic literature reviews. We see such differences as evidence of significant progress in the field, despite the issues we as a community have had in defining sustainability and SHCI's role in addressing it.

The first notable shift is that, in contrast to DiSalvo et al. 2010 [21] and Brynjarsdóttir et al. 2012 [7] in particular, the emerging categories reveal much less interest in understanding people in order to somehow change them. People are no longer conceived of as contributors to unsustainability; they are seen as a latent force for good in the fight for sustainability. Individuals' apathy and/or lack of information are no longer seen as appropriate targets for technological intervention. Recent work instead focuses on ways that technologies can support people (generally groups of people, often in their role as a citizen), to help them fight, to help them survive, to help them thrive. (This is, we think, different from both the "Users as the problem vs. solving users' problems" axes of difference identified in DiSalvo et al. [21].) It originates less from the discipline of psychology, therefore, and more from sociology, political science and even economics. As a result, the formerly evident boundaries between environmental SHCI, social SHCI and economic SHCI, as found in Knowles et al. 2013 [49], are no longer relevant.

There is also a clear difference in thinking regarding the function of sustainable technology - a shift from focusing on designing improvements in/through ICTs to designing change in/through them. For example, it is not the individual algorithms which need to be made more efficient (cf. [49]); in fact, any individual technology is not especially interesting. Much more interesting are questions on the order of how to make the computing industry sustainable, and how such change may be coordinated toward various goals, given the complexity of the systems with which we are tinkering. This makes for a much more diverse set of categories, and therefore a broader SHCI agenda, than was found in earlier surveys [7, 21, 47]-a somewhat counter-intuitive though pleasantly surprising outcome of having started from climate change as the uniting concern rather than sustainability.

The consequence of abandoning traditional sustainability in and through approaches [60]-i.e. at least by the segment of publications we have summarized in the previous sectionsis that these categories become less prescriptive, less assured. 
The kinds of SHCI activities that seem to meaningfully contribute toward sustainability are not those that solve welldefined problems, but rather those that contribute more subtly to a shift in culture or power. While this leaves us in the uncomfortable position of not necessarily knowing what to design [32], it does at least mean that we are looking in the right place for inspiration to strike.

Now, we do not mean to suggest that SHCI papers are in harmony with one another. That is decidedly not the form of progress we have identified in the field. Between the many works we have lumped together into these respective categories, there remains unarticulated and unresolved disagreement between researchers (cf. [21]). It would be more accurate to say that we think we have described a sub-set of categories within the broader SHCI community that have evolved in recent years, and that a kind of harmony can be negotiated between these categories by seeing them in a new light: as fitting with a single, coherent, inspiring sustainability narrative.

\section{The academic-industrial complex}

There is a larger discussion to be had about the forces that shape the landscape of published SHCI works. It is difficult to know whether many of the authors seemingly advocating incremental change are, in fact, in agreement with Klein but find it easier to get funded or published doing less radical work; or for that matter how many more publications there might have been aligning with this paper's vision that were not published via ACM SIGCHI. ACM's stated vision is to "see a world where computing helps solve tomorrow's problems... and make a positive impact" (https://www.acm.org/), but it is possible that understandings of what "positive impact" looks like (and what kinds of impacts are possible) are influenced by deep-seated assumptions about the benefits of economic growth and the role of the digital in fostering such growth. As such, we must consider the possibility that the criteria for inclusion in the $\mathrm{CHI}$ conference proceedings are influenced by the implicit pressure to contribute to the digital economy as more commonly envisaged within the discipline.

We do not know to what extent the ideologies within academia and within CHI make it hard to do the kind of SHCI work advocated in this paper. We certainly understand the instinct behind the other dominant view represented in SHCI (i.e. incremental change); but recognizing that this instinct arises through various influences on the discourse is quite different to accepting this state of affairs. It is notable how many of the works we have cited as being reconcilable with Klein are published through the comparatively tiny and quite recently established annual LIMITS workshop ${ }^{6}$. It may be that alternative venues for the publication of SHCI research may need to be developed as part of the project of radicalizing SHCI-in particular smaller venues which may be more open to "big ideas" or "new directions" [75]. But we feel that it is worth making a concerted effort to find ways of supporting such work in what has been SHCI's premier venue, i.e. $\mathrm{CHI}$, for example by presenting works such as this (ours)

\footnotetext{
${ }^{6}$ Since 2016, LIMITS is in cooperation with ACM, albeit through SIGCAS (Computers \& Society), rather than SIGCHI.
}

to see whether it sparks a shift in thinking about technology's role in affecting radically positive change.

\section{This changes what, exactly?}

The title of this paper is clearly an homage to Klein's work; and like her's, our title is not intended to be boastful. Rather, it is intended to signal the fact that we must "start the conversation ${ }^{7}$ about climate change [or SHCI, for us] in the right place" [100]. This would ostensibly imply-though clearly it remains to be debated-that there is no room for comfortable notions of technological quick fixes, or any kind of intervention that does not in some way address the root cause of climate change. The good news is that actually - to our surprise and delight- the community has seemingly brought itself to the brink of this conclusion already, without having stated it in such categorical terms. But stating it categorically is precisely what is needed if we are to move forward productively as a community. All we have done, therefore, is articulate the rationale underpinning the fear of many in the community (in particular those who are starting to pull away from SHCI) that there is no route to sustainability within our current economic system, and in laying this out, to (hopefully) enable us to address this fear head on. In doing so, we also hope we have shown that while SHCI researchers may prefer their own well crafted, nuanced definitions of sustainability, there is nonetheless a strong contingency in the community that is in agreement about the kind of change needed to arrest climate change. We believe the justice-based economy required to do so would affect greater sustainability according to the spirit of most researcher's definitions, including those advocating incremental change as the route to getting there. For this reason, we contend that the vision we have laid out here has the potential to promote more effective collaboration between the two formerly irreconcilable camps (incremental change vs. systemic change), though we understand that negotiating this collaboration will take some effort.

The remaining question that we cannot satisfactorily answer is whether the community needs a re-branding of sorts to reflect this new place we have arrived at. The term sustainability is demonstrably problematic, given the incompatibility of the myriad conceptions that surround it, and given that climate change is not necessarily afforded the prominent place it deserves in amongst the various issues indexed by sustainability. But then, if what we have proposed is seen as a call for a next wave of SHCI, it is nonetheless reflective of evolution which occurred within SHCI, and is therefore part of a legacy we can take some pride in. Removing the ' $S$ ' (and replacing it with what, 'CC'?) would seem to disavow that heritage.

\section{CONCLUSION}

What we have presented in this paper is bound to cause controversy. We are under no illusions: a proportion of the community will disagree with the details of the vision set forth; and some will undoubtedly object to the project attempted herein of articulating a shared vision to begin with. We felt

\footnotetext{
${ }^{7}$ To clarify, by this we do not mean we are starting a new conversation; rather we see this work as concretizing recurring discussions in the field.
} 
strongly, however, that it was important to illustrate the clarity that comes with pinning down a vision of SHCI going forward, and to invite the community to discuss this together. While we drew from many other voices in the field in formulating this vision, we also recognize that we have clearly argued in favor of one of the two dominant views represented by SHCI. We do not aim to be dictatorial; but equally we do not believe that all conceptions of sustainability have equal merit, and we fear that simultaneous pursuit of multiple ends may be counter-productive. Further, we understand this to be a controversial position that may, in fact, go against the view presented by Silberman et al. [94] which we (the authors) had contributed to only a few years ago.

Unfortunately, the 'procrastination penalty' applies to SHCI as it does to climate change. We have spent so long debating definitions of sustainability and SHCI, and being indecisive on a direction to pursue, that to have any reasonable chance of affecting change, we must make a bold and radical decision on a future course of action. Our own experiences in participating in numerous SHCI workshops and struggling to develop a shared community knowledge base [53] have convinced us that these mechanisms are not enough to bring the SHCI community together, so instead we have attempted a different tactic here: to elaborate a vision. We are, in doing so, advocating the privileging of a particular perspective on sustainability that a) is sufficiently radical to enable us to affect root causes of unsustainability, and b) is focused enough to enable us to conceive of research activities to undertake in concert as a community. Despite having spent so many years peeling back layers of the onion to discover added complexities and interconnections that make a singular definition of sustainability so elusive, there do appear to be points of leverage within Klein's conception of a sustainable future which, if we were to focus on these, would address the many and varied manifestations of unsustainability that would seem to motivate all researchers doing SHCI work.

Finally, we contend that 'doing good' - the nebulous aim that unifies all definitions of sustainability [4, 59]-is a noble goal, but not especially useful for orienting an HCI research agenda that challenges existing norms of HCI research (don't all researchers think they are contributing to a better world?), particularly when it requires each individual researcher to define what 'good' looks like. Without a clear vision that can be communicated to HCI more broadly, sustainability, and SHCI by extension, are easily dismissed as meaninglessas useful only in demarcating one's inclusion in a counterculture (e.g. tree-huggers) within HCI. Indeed, the moralizing connotations of the term sustainability when ill-defined has the potential to create a problematic us-versus-them culture within HCI, with us playing the role of nuisance or 'deviant' [52]. We hope that articulating a pragmatic vision of what HCI (notably, not just SHCI) needs to do to stay relevant in the project of realizing a sustainable future enables those who had been put off by sustainability rhetoric to understand the purpose of designing for sustainability within HCI, and why they too should be involved in the effort.

\section{ACKNOWLEDGMENTS}

This work has been funded by a personal grant from Chalmers University of Technology. A special thanks to Lynne Blair (Lancaster University) for providing feedback on an early draft of this work. And our sincere thanks to the anonymous reviewers for their help with shaping and improving this paper.

\section{REFERENCES}

1. Asad, M., and Le Dantec, C. A. Tap the "make this public" button: A design-based inquiry into issue advocacy and digital civics. In Proc. CHI '17, ACM (2017), 6304-6316.

2. Bates, O., Hazas, M., Friday, A., Morley, J., and Clear, A. K. Towards an holistic view of the energy and environmental impacts of domestic media and it. In Proc. CHI '14, ACM (2014), 1173-1182.

3. Bates, O., Lord, C., Knowles, B., Friday, A., Clear, A., and Hazas, M. Exploring (un) sustainable growth of digital technologies in the home. In Proc. ICT4S' 15, Atlantis Press (2015).

4. Bates, O., Thomas, V., and Remy, C. Doing Good in HCI: Can We Broaden Our Agenda? interactions (2017 (in press)).

5. Baumer, E. P., and Silberman, M. S. When the implication is not to design (technology). In Proc. CHI '11, ACM (2011), 2271-2274.

6. Blevis, E. Sustainable interaction design: Invention and disposal, renewal and reuse. In Proc. CHI '07, ACM (2007), 503-512.

7. Brynjarsdóttir, H., Håkansson, M., Pierce, J., Baumer, E., DiSalvo, C., and Sengers, P. Sustainably unpersuaded: how persuasion narrows our vision of sustainability. In Proc. CHI '12, ACM (2012), 947-956.

8. Busse, D., Blevis, E., Beckwith, R., Bardzell, S., Sengers, P., Tomlinson, B., Nathan, L., and Mann, S. Social sustainability: an HCI agenda. In Proc. CHI EA '12, ACM (2012), 1151-1154.

9. Busse, D. K., et al. CHI at the barricades: an activist agenda? In Proc. CHI EA '13, ACM (2013), 2407-2412.

10. Chen, J. A strategy for limits-aware computing. In Proc. LIMITS '16, ACM (2016), 1:1-1:6.

11. Clear, A. K., Preist, C., Joshi, S., Nathan, L. P., Mann, S., and Nardi, B. A. Expanding the boundaries: A SIGCHI HCI \& sustainability workshop. In Proc. CHI EA '15, ACM (2015), 2373-2376.

12. Crabtree, A., and Chamberlain, A. Making it "Pay a Bit Better": Design challenges for micro rural enterprise. In Proc. CSCW' 14, ACM (2014), 687-696.

13. Crabtree, A., Chamberlain, A., Valchovska, S., Davies, M., Glover, K., and Greenhalgh, C. "I've Got a Sheep 
with Three Legs if Anybody Wants It?": Re-visioning the rural economy. Personal Ubiquitous Comput. 19, 8 (Dec. 2015), 1247-1258.

14. Crivellaro, C., Comber, R., Bowers, J., Wright, P. C., and Olivier, P. A pool of dreams: Facebook, politics and the emergence of a social movement. In Proc. CHI '14, ACM (2014), 3573-3582.

15. Crivellaro, C., Comber, R., Dade-Robertson, M., Bowen, S. J., Wright, P. C., and Olivier, P. Contesting the city: Enacting the political through digitally supported urban walks. In Proc. CHI'15, ACM (2015), 2853-2862.

16. Davison, A. Technology and the contested meanings of sustainability. Suny Press, 2001.

17. Diamond, M. The story of toxic chemicals in computing systems. In Proc. LIMITS '17, ACM (2017), 1-1.

18. Dillahunt, T. Toward a deeper understanding of sustainability within HCI. In CHI'14 workshop on Sustainability. What Have We Learned? (2014), http://chi2014sust.120cell.org/papers/dillahunt.pdf.

19. Dillahunt, T., Mankoff, J., Paulos, E., and Fussell, S. It's not all about green: Energy use in low-income communities. In Proc. UbiComp '09, ACM (2009), 255-264.

20. DiSalvo, C., Light, A., Hirsch, T., Le Dantec, C. A., Goodman, E., and Hill, K. HCI, Communities and Politics. In CHI'10 Extended Abstracts on Human Factors in Computing Systems, CHI EA '10, ACM (New York, NY, USA, 2010), 3151-3154.

21. DiSalvo, C., Sengers, P., and Brynjarsdóttir, H. Mapping the landscape of sustainable HCI. In Proc. CHI'10, ACM (2010), 1975-1984.

22. Dombrowski, L., Brubaker, J. R., Hirano, S. H., Mazmanian, M., and Hayes, G. R. It takes a network to get dinner: designing location-based systems to address local food needs. In Proc. UbiComp '13, ACM (2013), 519-528.

23. Dombrowski, L., Harmon, E., and Fox, S. Social justice-oriented interaction design: Outlining key design strategies and commitments. In Proc. DIS '16, ACM (2016), 656-671.

24. Dombrowski, L., Voida, A., Hayes, G. R., and Mazmanian, M. The labor practices of service mediation: A study of the work practices of food assistance outreach. In Proc. CHI' 12, ACM (2012), 1977-1986.

25. Dourish, P. HCI and environmental sustainability: The politics of design and the design of politics. In Proc. DIS '10, ACM (2010), 1-10.

26. Easterbrook, S. From computational thinking to systems thinking. In Proc. ICT4S '14, Atlantis Press (2014).
27. Ekbia, H., and Nardi, B. Social inequality and HCI: The view from political economy. In Proc. $\mathrm{CHI}$ '16, ACM (2016), 4997-5002.

28. Foth, M., Parra Agudelo, L., and Palleis, R. Digital soapboxes: Towards an interaction design agenda for situated civic innovation. In Proc. UbiComp '13 Adjunct, ACM (2013), 725-728.

29. Ganglbauer, E., Fitzpatrick, G., Subasi, O., and Güldenpfennig, F. Think globally, act locally: A case study of a free food sharing community and social networking. In Proc. CSCW'14, ACM (2014), 911-921.

30. Ganglbauer, E., Reitberger, W., and Fitzpatrick, G. An activist lens for sustainability: From changing individuals to changing the environment. In Proc. PERSUASIVE'13, Springer-Verlag (2013), 63-68.

31. Goodman, E. Three environmental discourses in human-computer interaction. In Proc. CHI EA '09, ACM (2009), 2535-2544.

32. Håkansson, M., and Sengers, P. No easy compromise: Sustainability and the dilemmas and dynamics of change. In Proc. DIS '14, ACM (2014), 1025-1034.

33. Hansen, J., Sato, M., Kharecha, P., Beerling, D., Berner, R., Masson-Delmotte, V., Pagani, M., Raymo, M., Royer, D. L., and Zachos, J. C. Target atmospheric CO2: Where should humanity aim? arXiv preprint arXiv:0804.1126 (2008).

34. Harvey, J., Golightly, D., and Smith, A. HCI as a means to prosociality in the economy. In Proc. $\mathrm{CHI}$ '14, ACM (2014), 2955-2964.

35. Hazas, M., Brush, A. J. B., and Scott, J. Sustainability does not begin with the individual. interactions 19, 5 (Sept. 2012), 14-17.

36. Heitlinger, S., Bryan-Kinns, N., and Jefferies, J. UbiComp for grassroots urban food-growing communities. In Proc. UbiComp '13 Adjunct, ACM (2013), 589-594.

37. Hilty, L. M. Computing efficiency, sufficiency, and self-sufficiency: A model for sustainability? In Proc. LIMITS '15 (2015), 15-16.

38. Irani, L., and Silberman, M. S. From critical design to critical infrastructure: Lessons from Turkopticon. interactions 21, 4 (July 2014), 32-35.

39. Irani, L., Vertesi, J., Dourish, P., Philip, K., and Grinter, R. E. Postcolonial computing: A lens on design and development. In Proc. CHI '10, ACM (2010), 1311-1320.

40. Irani, L. C., and Silberman, M. S. Stories we tell about labor: Turkopticon and the trouble with "design". In Proc. CHI'16, ACM (2016), 4573-4586.

41. Jang, E., Johnson, M., Burnell, E., and Heimerl, K. Unplanned obsolescence: Hardware and software after collapse. In Proc. LIMITS '17, ACM (2017), 93-101. 
42. Jen, B., Kaur, J., De Heus, J., and Dillahunt, T. R. Analyzing employment technologies for economically distressed individuals. In Proc. CHI '14, ACM (2014), 1945-1950.

43. Joshi, S., Cerratto Pargman, T., Andreas, G., and Pargman, D. Whose future is it anyway? Limits within policy modeling. Journal of the ACM (06 2016).

44. Joshi, S., and Pargman, T. C. In search of fairness: Critical design alternatives for sustainability. In Proc. $A A$ '15, Aarhus University Press (2015), 37-40.

45. Kannabiran, G. Social equity and ecological sustainability in HCI: An ecofeminist perspective. In Proc. CHI EA '15, ACM (2015), 203-206.

46. Klein, N. This Changes Everything: Capitalism Vs. the Climate. Simon and Schuster, 2014.

47. Knowles, B. Re-imagining persuasion: designing for self-transcendence. In Proc. CHI EA '13, ACM (2013), 2713-2718.

48. Knowles, B., Blair, L., Coulton, P., and Lochrie, M. Rethinking Plan A for sustainable HCI. In Proc. CHI '14, ACM (2014).

49. Knowles, B., Blair, L., Hazas, M., and Walker, S. Exploring Sustainability Research in Computing: Where we are and where we go next. In Proc. UbiComp '13, ACM (2013), 305-314.

50. Knowles, B., Blair, L., and Walker, S. Cyber-sustainability: towards a sustainable digital future. $\mathrm{PhD}$ thesis, Lancaster University, 2013.

51. Knowles, B., Blair, L., Walker, S., Coulton, P., Thomas, L., and Mullagh, L. Patterns of persuasion for sustainability. In Proc. DIS '14, ACM (2014), 1035-1044.

52. Knowles, B., and Eriksson, E. Deviant and guilt-ridden: Computing within psychological limits. First Monday 20, 8 (2015).

53. Knowles, B., and Håkansson, M. A sustainable HCI knowledge base in progress. interactions 23, 3 (2016), 74-76.

54. Knowles, B., Lochrie, M., Coulton, P., and Whittle, J. BARTER: a technology strategy for local wealth generation. IT Professional 16, 3 (2014), 28-34.

55. Lee, Y.-H., and Hsieh, G. Does slacktivism hurt activism?: The effects of moral balancing and consistency in online activism. In Proc. CHI '13, ACM (2013), 811-820.

56. Light, A., and Briggs, J. Crowdfunding platforms and the design of paying publics. In Proc. CHI '17, ACM (2017), 797-809.

57. Light, A., Powell, A., and Shklovski, I. Design for existential crisis in the anthropocene age. In Proc. $C \& T$ '17, ACM (2017), 270-279.
58. Linehan, C., Kirman, B. J., Reeves, S., Blythe, M. A., Tanenbaum, J. G., Desjardins, A., and Wakkary, R. Alternate endings: Using fiction to explore design futures. In Proc. CHI EA '14, ACM (2014), 45-48.

59. Mankoff, J. HCI and sustainability: a tale of two motivations. interactions 19, 3 (May 2012), 16-19.

60. Mankoff, J. C., Blevis, E., Borning, A., Friedman, B., Fussell, S. R., Hasbrouck, J., Woodruff, A., and Sengers, P. Environmental sustainability and interaction. In Proc. CHI EA '07, ACM (2007), 2121-2124.

61. McDonald, S., Nardi, B., and Tomlinson, B. Political realities of digital communication: The limits of value from digital messages to members of the US congress. In Proc. LIMITS '17, ACM (2017), 129-138.

62. Meyers, E. M., and Nathan, L. P. Impoverished visions of sustainability: Encouraging disruption in digital learning environments. In Proc. CSCW'16, ACM (2016), 222-232.

63. Moulder, V., Boschman, L. R., Wakkary, R., Odom, W., and Kuznetsov, S. HCI interventions with nonprofit organizations: Tactics for effective collaboration. In Proc. CHI EA '14, ACM (2014), 877-880.

64. Nardi, B. The role of human computation in sustainability, or, social progress is made of fossil fuels. In Handbook of Human Computation. Springer, 2013, 1011-1020.

65. Nardi, B. Designing for the future: but which one? interactions 23, 1 (2015), 26-33.

66. Nardi, B. Inequality and limits. First Monday 20, 8 (2015).

67. Nathan, L. P., Kaczmarek, M., Cheng, S., Mann, R., et al. Good for whom?: Unsettling research practice. In Proc. C\&T '17, ACM (2017), 290-297.

68. Nathan, L. P., and Meyers, E. M. Enriching visions of sustainability through informal public pedagogies. interactions 23, 5 (2016), 54-57.

69. Pantidi, N., Ferreira, J., Balestrini, M., Perry, M., Marshall, P., and McCarthy, J. Connected sustainability: Connecting sustainability-driven, grass-roots communities through technology. In Proc. C\&T'15, ACM (2015), 161-163.

70. Pargman, D., Eriksson, E., and Friday, A. Limits to the sharing economy. In Proc. LIMITS '16, ACM (2016), 12:1-12:7.

71. Pargman, D., and Raghavan, B. Rethinking sustainability in computing: From buzzword to non-negotiable limits. In Proc. NordiCHI '14, ACM (2014), 638-647.

72. Pargman, D., and Wallsten, B. Resource scarcity and socially just internet access over time and space. In Proc. LIMITS '17, ACM (2017), 29-36. 
73. Pargman, T. C., and Joshi, S. Understanding limits from a social ecological perspective. First Monday 20, 8 (2015).

74. Parker, A., Kantroo, V., Lee, H. R., Osornio, M., Sharma, M., and Grinter, R. Health promotion as activism: Building community capacity to effect social change. In Proc. CHI '12, ACM (2012), 99-108.

75. Patterson, D. A. The health of research conferences and the dearth of big idea papers. Commun. ACM 47, 12 (Dec. 2004), 23-24.

76. Patterson, D. J. Haitian resiliency: A case study in intermittent infrastructure. First Monday 20, 8 (2015).

77. Paulos, E., Foth, M., Satchell, C., Kim, Y., Dourish, P., and Choi, J. H.-j. Ubiquitous sustainability: Citizen science $\&$ activism (workshop).

78. Penzenstadler, B., Raturi, A., Richardson, D. J., Silberman, M. S., and Tomlinson, B. Collapse (and other futures) software engineering. First Monday 20, 8 (2015).

79. Penzenstadler, B., Tomlinson, B., Baumer, E., Pufal, M., Raturi, A., Richardson, D., Cakici, B., Chitchyan, R., Da Costa, G., Dombrowski, L., et al. ICT4S 2029: What will be the systems supporting sustainability in 15 years. In Proc. ICT4S '14, vol. 2, Atlantis Press (2014), 30-39.

80. Piccolo, L. S. G., Alani, H., De Liddo, A., and Baranauskas, C. Motivating online engagement and debates on energy consumption. In Proc. WebSci '14, ACM (2014), 109-118.

81. Preist, C., Busse, D. K., Nathan, L. P., and Mann, S. POST-SUSTAINABILITY: a CHI sustainability community workshop. In Proc. CHI EA '13 (2013), 3251-3254.

82. Preist, C., Schien, D., and Blevis, E. Understanding and mitigating the effects of device and cloud service design decisions on the environmental footprint of digital infrastructure. In Proc. CHI '16, ACM (2016), 1324-1337.

83. Prost, S., Mattheiss, E., and Tscheligi, M. From awareness to empowerment: Using design fiction to explore paths towards a sustainable energy future. In Proc. CSCW'15, ACM (2015), 1649-1658.

84. Prost, S., Schrammel, J., and Tscheligi, M. 'Sometimes It's the Weather's Fault': Sustainable HCI \& political activism. In Proc. CHI EA '14, ACM (2014), 2005-2010.

85. Raghavan, B., Nardi, B., Lovell, S. T., Norton, J., Tomlinson, B., and Patterson, D. J. Computational agroecology: Sustainable food ecosystem design. In Proc. CHI EA '16, ACM (2016), 423-435.

86. Raghavan, B., and Pargman, D. Means and ends in human-computer interaction: Sustainability through disintermediation. In Proc. CHI '17, ACM (2017), 786-796.
87. Rahemtulla, H., Haklay, M., and Longley, P. A. A mobile spatial messaging service for a grassroots environmental network. Journal of Location Based Services 2, 2 (2008), 122-152.

88. Remy, C., and Huang, E. M. Sustainable interaction design: Obsolescence in a future of collapse and resource scarcity. First Monday 20, 8, 1-7.

89. Ross, J., Irani, L., Silberman, M. S., Zaldivar, A., and Tomlinson, B. Who are the crowdworkers?: Shifting demographics in Mechanical Turk. In Proc. CHI EA '10, ACM (2010), 2863-2872.

90. Shroff, G., and Kam, M. Towards a design model for women's empowerment in the developing world. In Proc. CHI'11, ACM (2011), 2867-2876.

91. Silberman, M. S. Information systems for the age of consequences. First Monday 20, 8 (2015).

92. Silberman, M. S., Blevis, E., Huang, E., Nardi, B. A., Nathan, L. P., Busse, D., Preist, C., and Mann, S. What Have We Learned?: A SIGCHI HCI \& Sustainability Community Workshop. In Proc. CHI EA '14, ACM (2014), 143-146.

93. Silberman, M. S., Irani, L., and Ross, J. Ethics and tactics of professional crowdwork. XRDS 17, 2 (Dec. 2010), 39-43.

94. Silberman, M. S., Nathan, L., Knowles, B., Bendor, R., Håkansson, M., Dillahunt, T., and Mankoff, J. Next steps for sustainable HCI. interactions 21, 5 (2014), 66-69.

95. Simm, W., Ferrario, M. A., Friday, A., Newman, P., Forshaw, S., Hazas, M., and Dix, A. Tiree energy pulse: Exploring renewable energy forecasts on the edge of the grid. In Proc. CHI'15, ACM (2015), 1965-1974.

96. Strengers, Y. Smart energy in everyday life: Are you designing for resource man? interactions 21, 4 (2014), 24-31.

97. Strengers, Y., Nicholls, L., and Maller, C. Curious energy consumers: Humans and nonhumans in assemblages of household practice. Journal of Consumer Culture 16, 3 (2016), 761-780.

98. Tanenbaum, J., Pufal, M., and Tanenbaum, K. The limits of our imagination: design fiction as a strategy for engaging with dystopian futures. In Proc. LIMITS '16, ACM (2016), 10:1-10:9.

99. Tanenbaum, J. G., Williams, A. M., Desjardins, A., and Tanenbaum, K. Democratizing technology: Pleasure, utility and expressiveness in DIY and maker practice. In Proc. CHI' 13, ACM (2013), 2603-2612.

100. The Guardian. Naomi Klein: This Changes Everything live with Owen Jones. https://www.youtube.com/watch?v=dhJA7HCPHDA, December 2014. 
101. Thomas, V., Remy, C., and Bates, O. E. G. The limits of HCD: reimagining the anthropocentricity of ISO 9241-210. In Proc. LIMITS '17, ACM (2017), 85-92.

102. Thomas, V., Remy, C., Hazas, M., and Bates, O. HCI and environmental public policy: opportunities for engagement. In Proc. CHI '17, ACM (2017), 6986-6992.

103. Tomlinson, B., et al. What if sustainability doesn't work out? interactions 19, 6 (Nov. 2012b), 50-55.

104. Tomlinson, B., Nardi, B., Patterson, D. J., Raturi, A., Richardson, D., Saphores, J.-D., and Stokols, D. Toward alternative decentralized infrastructures. In Proc. DEV'15, ACM (2015), 33-40.

105. Tomlinson, B., Silberman, M. S., Patterson, D., Pan, Y., and Blevis, E. Collapse informatics: Augmenting the sustainability \& ICT4D discourse in HCI. In Proc. CHI '12, ACM (2012), 655-664.
106. Vlachokyriakos, V., Comber, R., Crivellaro, C., Taylor, N., Kuznetsov, S., Kavanaugh, A., Le Dantec, C. A., and Kim, B. J. Designing alternative systems for local communities. In Proc. CHI EA '15, ACM (2015), 2333-2336.

107. Wakkary, R., Desjardins, A., Hauser, S., and Maestri, L. A sustainable design fiction: Green practices. ACM Trans. Comput.-Hum. Interact. 20, 4 (Sept. 2008), 23:1-23:34.

108. Woodruff, A., Hasbrouck, J., and Augustin, S. A bright green perspective on sustainable choices. In Proc. CHI '08, ACM (2008), 313-322.

109. Yoo, D., Lake, M., Nilsen, T., Utter, M. E., Alsdorf, R., Bizimana, T., Nathan, L. P., Ring, M., Utter, E. J., Utter, R. F., et al. Envisioning across generations: A multi-lifespan information system for international justice in Rwanda. In Proc. CHI '13, ACM (2013), 2527-2536. 